\title{
Fra Flensborg danske Præstegaard o. 1864.
}

Af H. F. Petersen.

Nedenfor skal optrykkes et Par Breve fra Pastor Graae i Flensborg til Biskop D a u g a a r d i Ribe.

Pastor G. Fr. A. Gra a e var født den 23. August 1810 i Bøstrup Præstegaard paa Langeland - Forældrene findes jo i Kaj Munks "Egelykke" - og ansattes, efter at have virket ved St. Cathrine Kirke i Ribe, den 22. April 1851 som Sognepræst ved den nyoprettede frie danske Menighed i Flensborg, der fik cverladt Helligaandskirken til Brug.

De fortrolige Breve, Graae sender sill gamle Ven, Biskop D a u g a a r d, giver et levende Indblik i hans Personlighed og Tankegang under spændende ydre Forhold. Derfor kan det maaske have sin Interesse at drage dem frem netop nu. ${ }^{1}$ )

Det siger sig selv, at Pastor Graaes Anskuelser og frimodige Udtryksmaade ganske staar for hans egen Regning. De er fremsatte i private Breve uden Tanke paa Offentliggørelse.

*

Flensborg, 18. Dec 185ti.

Da jeg $\mathrm{i}$ en halv Snes Dage havde maattet holde mig inde paa Grund af en Byld paa Armen, var det tilfældigt, at jeg igaar ved at blade om i "Berl. Tid.« stødte paa Deres Navn, kjære Hr. Biskop! og saa da, at det var en Dødsanmeldelse! Ganske uventet kom vel denne Sorg ikke over Dem, men derfor er den ikke mindre. Jeg har ofte med hiertelig Deltagelse tænkt paa Dem og Deres i den Anledning, og tager nu ogsaa oprigtig Del i denne nye Familiesorg; men jeg ved, at De er ikke uden Trøst, men har et Hjerte og et Hus, hvor Juleglæden har fundet og vil fremdeles finde Indgang. Deres Søn var jo

1) Brevene er utrykte og findes paa det kongelige Bibliotek i København (Ny kgl. S. 2795. 4.). Pastor Graae har jeg skildret i "Danske i Sydslesvig", Kbh. 19:33, S. $28 \mathrm{ff}$, og Breve til andre har jeg gengivet i "Fra sydslesvigske Præstegaarde», Khh. 1938, S. 29 ff. 
et fromt og dybt Gemyt, og det er sandelig en velsignet Ting at vide om de Døde, at de ere døde i Herren. Deri samler sig jo al vor Trøst, naar vi gaa tilbunds i Tingene; og Gud være lovet, at $\mathrm{De} \mathrm{i}$ den Henseende vist kan være saa ubekymret og frimodig som Nogen, - De, den kjærlige og christelige Fader, der kan bære meget, og mange med Dem, i den Kjærlighed, der tror Alt, haaher Alt, taaler Alt; og i Deres kjærlige fortræffelige Hustru ved jeg, De har en Veninde, som kan og vil dele Alt med Dem i den samme Kjærlighed. -

Forbindelsen mellem Ribe og Flensborg er for mit Vedkommende, hvad Correspondancen angaar, tarvelig nok og stundom saa længe afbrudt, at man skulde tro, Store Belt med Sprogø laa imellem os i en Fimbulvinter, - saaledes gaar det her i Verden. Aanden er villig, men Kjødet er skrøbeligt, selv hvor det kun gjælder om at sætte Pennen til Papiret. Jeg er en stor Synder i deme som i saa mange andre Henseender. Saa'ænge jeg Intet hører fra gamle Venner og Bekjendte, slaar jeg mig til Ro i den Tanke, at Alt vel gaar sin jævne Gang, men paa den jævne Gang følger Slutningshastigheden, inden man ved af det! - Hos os gaar det saa-saa i denne Tid. Thomas har Kighoste og Thyra begynder at faa den; den ene Pige er syg og dell anden er ikke rask; min Svigerindes Helbred er skrøbeligt, saa at hun taaler ikke meget, men hun er meget taalmodig; min Kone, som skulde plejes, maa pleje og passe de Mange, der bliver flere og flere. Jeg har jo rigtignok havt en Byld, og det endda en "Svinebyld", men forøvrigt er jeg hjertefrisk og lettilbens endnu, og kan egentlig ikke rigtig forstaa, at jeg snart er en gammel Dreng. "Kald ham graa, og lad ham gaa!" Min bedste Glade har jeg i mit $\mathrm{H}$ j e m, hvor Kone og Børn er ganske skikkelige, og i min $\mathrm{K}$ i $\mathbf{r}$ e hos min ecclesiola, der ogsaa udgjør en ganske kjøn lille Familie. Vi omgaaes faa, færre og færre, til dagligt Brug. Nervus rerum gerendarum [Pengene] vil jo ikke altid strække til; men man slider jo Tiden og har ingen Nød, naar der kun er lidt Olie i Lampen. Det Nyeste-Nyt, jeg har at fortælle herfra, skriver sig da fra Stænderforsamlingens 
Aabning. Den bekjendte Thies $\mathrm{s}$ [Provst for Sydangel] holdt den tyske Prædiken, og, med Skam at tale, var det morsomt. nok at se og høre, hvordan han kunde tumle sig deroppe, -.kunde de danske Skuespillere gjøre deres Sager saa godt, saa tror jeg virkelig, at jeg igjen kunde faa Lyst til at gaa paa Komedie. Forresten kan man ikke nægte, at han er en god Fægtemester. Hans Prædiken kommer i Trykken, og saa kan De jo læse den, men "det levende Ord«, baaren af en tysk Vind, kommer De til at undvære. - Ved Gildet passerede her en anden Mærkelighed. Den brave Provst [Sophus Aleth] Hansen udbragte en Skaal for "Gamle Danmark «, hvori han lod falde nogle Ord om "Dannevirke" som et Værn mod "næsvise Fremmede, der gjerne vilde blande sig i vore Anliggender". Det foranledigede Obersachwalter für das Herzogthum Schleswig, $\mathbf{S} \mathbf{c h} \mathbf{~ m}$ i d t von L e d a genannt von Hattenstein, (forhen Medlem af Landesversammlung i Kiel), nu Ridder af Dannebrog, item 1ste Medl. af Appellationsretten B a g g er, ligeledes Ridder af Dannebrog, til efter Bordet at forlange en Erklæring af Provsten over, hvad han forstod ved "Gamle Danmark " osv., da det syntes at smage af Danmark til Ejderen osv. - Hansen afviste da Fordringen som uberettiget og frabad sig videre Spergsmaal, men det er dog et stærkt Stykke, at saadanne "Kerls«, især da den Hr. von L ed a, tør vove at gjøre Indsigelse mod "Gamle Danmark«. Jeg, som hører til Dii minorum gentium (eller mindre Profeter), skal forst med til Stændergildet Nr. 2 idag, og kom saaledes ikke i Fristelse til ved hin Lejlighed at rage uklar med den "Lede«; men det kan jo naaes en anden Gang! -

Der kunde endnu være meget, saare meget at skrive om; men hvor skal man begynde og hvor skal man ende, naar man vil gjennemløbe vore kirkelige Stridigheder? Nu, i Guds Navn! det kan ogsaa blive godt, om man springer en hel Del af det over; - i næste Uge er det jo Juleaften; kan man saa blot komme til Bethlehem og være glad med de Glade her og.med "Puslingerne« omkring os, saa kunne vi gjerne indtil videre lade "Vilderedet« skjøtte sig selv. 
Vor Herre give Dem og alle Deres en glædelig Jul og et lyksaligt Nytaar! Det er mit og alle Mines Ønske og Hilsen. Vil De bringe den samme Hilsen til Bispinde Mollers, Stiftsprovstens og min gamle Ven Klokkeren ved St. Kathrine Kirke, saa skal De have Tak! -

Levvel og tænk imellem paa

Deres med Højagtelse og Venskab hengivne G. F. Graae.

13. Oktober 1858.

Det er længe, siden jeg skrev til Deres Højærværdighed, og jeg vil derfor ikke opsætte det længere. Med Deres Søn fik jeg vel en Hilsen sendt Dem og Deres Familie, men jeg laenges nu ret meget efter engang igjen at høre, hvorledes De og alle Deres lever. Deres Søns Helbredstilstand var endnu i Sommer noget vaklende; det vilde glæde min Kone og mig meget at høre, at han nu befandt sig bedre. Medens vi dagligt kom sammen, gik alt saa godt, men Tiden fører mange Sorger og Bekymriuger med sig. De er jo rask vel, men de lange og besværlige V'isitatsrejser kunne dog maaske snart begynde at genere Dem mere end forhen. Dog gjør jeg Regning paa, at Deres gode Humeur har en saa solid Grund, at det nok endnu med Guds Hjelp kan overvinde en Del Bryderier og trodse, om det saa skal være, adskillige Storme! -

Jeg sendte forleden Dag en Hilsen til Dem med Deres nye Vice-Pastor i Jernved; lad mig lægge en Forben ind for ham med Hensyn til den forestaaende examen rigorosum. Han har sikkert svedt sin Latin ud, og af Theologia er der vist heller ikke meget mere end Ruiner tilbage, som der maaske behøves en Lajards skarpe Øjne til at opdage. $\left.{ }^{2}\right)$ Men Barfod i Sørup siger, at det er et skikkeligt Menneske, og han skal prædike meget opbyggelig. Vær derfor naadig og barmhjertig! Har Vor Herre holdt Liv i ham saa længe, til han fik et Embede, saa

${ }^{2}$ ) (I Marginen) Jeg vilde give meget Godt til, at jeg kunde sidde i en Krog og høre paa den Examen! Men jeg ser Dem for mine Øjne. 
maa De da nu se Dem for, at De ikke tager saa haardt paa ham, at han skulde dø under Deres biskoppelige Hænder! - Han har levet i saa tarvelige Kaar, at han er fast ligesom en Robinson Crusoe! Da han saa min Præstekjole, listede han sig nær hen for at tage den rigtig i Øjesyn: "Den er jo foret; saa maa der vist ogsaa Foder i min; det talte ellers Skrædderen ikke om! «"Ja", svarede jeg, "De maa ikke blot have Foder i Kjolen, men en Skindpels indenunder, ellers fryser De ihjel til V'inter!« Men, som sagt: vær nu god imod ham til den Examen! Jeg frygter virkelig for, at Deres megen Lærdom skal gjgre ham rasende! Naar jeg nu saa varmt anbefaler den gamle skikkelige Stymper, saa kan De da idetmindste være vis paa, at han ikke har bestukket mig med Sølv eller Guld; thi han er vist en rigtig fattig Kirkerotte! -

Nu maa jeg dog fortælle Dem, hvor kjønt mine gamle Venner paa Langeland have behandlet mig: - igaar fik jeg saamænd en Skrivelse af 7 de dennes fra Sogneforstanderskabet i Lindelse paa Langeland (hvor jeg for 20 Aar siden var Kapellan), hvori Samme paa Menighedens Vegne opfordrer mig til at søge Lindelse. Det gjør jeg nu vel ikke; men det var mig dog en kjær Erindring fra gamle Dage! Embedet er med disse Kornpriser nok lidt bedre end det, jeg har; men Flytning og Naadesaar (da jeg $i$ et helt Aar skulde leve af et halvt Embede, eftersom her ikke er Naadesaar ved dette Embede) vilde jo forøge min Gjæld meget betydelig, og naar jeg ikke kan forbedre mine Kaar, vil og bør jeg ikke forlade min Post her. -

Menigheden er voxet meget; den tæller nu ikke saa lidt over 350 Familier (hvormange Individer ved jeg ikke saa bestemt); vi have nu bygget en dansk Borgerskole til, som skal indvies paa Tirsdag. Vi have i Alt vel omtrent 220 Skolebørn. -

Jeg havde næsten tænkt, at De eller Stiftsprovsten eller begge tilsammen var kommen herned for at hilse paa Kongen til hans Fødselsdag [6. Oktober]. - Jeg tænker, at jeg er paa det sorte Brædt; der tales en Del om, at Præstek on er 1 e 
(- paa min Katechets ${ }^{3}$ ) Kone nær! -) ikke som alle andre Embedsmandskoner have gjort deres Opvartning for Mada mm en [Grevinde Danner] derude [paa Lyksborg Slot]; men det faar saa være! Pokker skulde gør det, naar Man ikke er nødt til det! Det er mig et uhyggeligt Væsen; - desuden er det jo bekosteligt. Imorgen er der Bal derude; B i s pen [U. S. Boesen] med Kone, Døtre og Søn skal nok derud (item Katechetens!); han har længe været forkjølet og kjørte endnu idag til Kirke, da han gik til Alters, saa han vist hellere maatte blive hjemme imorgen, især da Ingen af Døtrene dandse; - men Bisper er ogsaa Mennesker.

Kjære gode Biskop Daugaard!

9. Maj 1864 .

Tak, inderlig Vak for Deres kjærlige Linier i denne for os alle saa tunge Tid! Vær overbevist om, at enten jeg skriver eller ej, lever De i min allerhjærteligste Erindring. Deres venlige Billede staar ofte for mig, og i Aanden faar jeg ikke saa sjælden en broderlig Samtale med min gode gamle Riber-Bisp!

Tiden tillader ikke at gaa nærmere ind paa Alt, hvad der ellers kunde være at tale om, hvis vi sad sammen i god Ro eller spadserede i al Gemytlighed som i gamle Dage. For Tiden give Lazaretterne os saa meget at bestille, at vi, saa at sige, lade Verden fremefter skjøtte sig selv. Efter den 18de [Dybbøldagen] bragtes hertil vel omtr. 300 danske Saarede, men deraf har jeg begravet $1 / 6$. Her er saa mange $L$ a $z$ a $r$ et t e $r$, at Man, for dog at udrette Noget, maa indskrænke sig til enkelte af dem. Katechet Munck og Pastor Ewaldsen ere tro Medhjælpere; men foruden os Præster ere der Gudskelov! mange Andre, baade Mænd og Kvinder, der opofre sig for de stakkels Saarede. Min gode Degn T of t e er bl. a. en mageløs Mand, og saa er der adskillige Borgere, som udrette saare meget, navnlig fremfor Alle en Garvermester J a k o b P la et ner. Damer have fordelt La-

3) Katechet var fra 1855-62 Pastor Gad, fra 1862-64 Pastor Vilhelm Munck. 
zaretter imellem sig, saaledes at et Par have hver sit, og de Saarede Danske og Prøjsere, ligge mellem hverandre paa 17-18 Steder. Min Kone og jeg følges ad hver Eftermiddag: til et Par af de største Lazaretter, min Svigerinde Fru Bretteville gaar paa andre, og saaledes en Mængde Andre. Det er de danske Damer, som have Aren af forst at have ydet de Saarede personlig Hjælp og Opmuntring. De Tyske vilde ikke være ringere og vilde nu gjerne fortrænge de Andre; det er den ulykkelige Splid, som gjentager sig allevegne; men det tor jeg nok sige, at det er en god Aand, som er over de dansksindede Flensborgere, medens den tysksindede Del er fanatiseret af Had til [de] Danske og ellevild af Glæde over den Forandring, der er foregaaet. $\mathrm{Nu}$, Enden er ikke endda! - Hvad der skal udvikle sig af dette Chaos, ved intet Menneske, og jeg for min Del lader ogsaa p. T. "hver Dag have nok i sin Plage!«-

I Eftermiddag har min Kone og jeg havt en sørgelig Gang; i „Generalkommandoen" fandt vi en af vore kjæreste Jenser død 1/2 Time iforvejen; der laa et Tæppe over en død Soldat, og da jeg trak det tilside, var det netop den, som vi vilde bringe et Brev fra hans Kone. Derfor gik vi til "Harmonien«, hvor en gammel skikkelig Reserveofficeer, Ras mus en (fra Hesselballe i Uldum) droges med Døden. I Formiddags døde en Lieut. M o g e n s e n paa "Bellevue", og saaledes gaar det hver Dag, da her er saa mange haardt saarede. - De prøjs. Læger ere i det Hele taget flinke, og paa "Søstre" og Munke mangler det jo heller ikke, og adskillige af dem gjøre megen Gavn, især "Søstrene" fra "Bethanien", som ere paa Johanniterhospitalerne. Jeg har adskillige Gange holdt Gudstjeneste paa et Par af Lazaretterne, hvor forøvrigt Danske og Prøjsere ligge meget venskabelig ved hverandres Side, hvilket i Grunden gjor et godt Indtryk netop for Modsætningens Skyld i denne Krigstid. -

Jeg sidder endnu uforstyrret i mit Embede - saa længe det varer! Den danske Borgerskole er heller ikke ophævet, skjøndt reduceret til 2 lejede Stuer, da de 2 store Skolebygninger ere tagne til Lazaretter, som er slemt nok, da vi have 500 Børn. .- 
Det gjælder om at være snilde som Slanger og enfoldige som Duer; - i P[røjserne] have vi, hvad det Første angaar, vore Mestre! - Ja, hvad har Man ikke oplevet i det sidste ${ }^{1 / 2}$ Aar!! Hvormange - for at nævne et - hvormange af vore bedste Venner her og i Omegnen ere ikke borte! - og dog, vi ere nærved ikke at savne dem; 1) fordi vi have Andet at tanke paa; 2) fordi alle Danske og Dansksindede her nu udgjøre et eneste stort Brodersamfund.

Her i Huset ere vi, Gudskelov! raske; min Kone og hendes Soster Fru Bretteville, den tapre $\mathrm{Th}$ o mas og den fornøjelige lille Ingeborg ere her; - Tante Marie, Olivia, Dorothea, Lorenze og Thy ra sendte vi til Kjøbenhavn umiddelbart før Tilbagetoget, hvor de have havt det godt. $0 . \&$ D. ere nu i Skaane hos deres Onkel S u hr, der ejer en Gaard der. Th. tog jeg naturligvis strax ud af den forpestede Latinskole, og jeg har nu søgt om at faa ham til Herlufsholm. Det er en rask og opvakt Dreng, flink til Bogen, men dog i Tanken allerede Soldat.

Fortsat 10. 5. 64:

Igaar blev en Gammellutheraner, Feltpræst B e s s e r (Forf. til et Bibelværk, der er overs. paa D.) indqvarteret her. Vi talte og disputerede sammen inat til Kl. $2^{1 / 4}$, og som Følge deraf sov han over sig imorges og kom ikke med Jernbanen. En interessant og dannet Mand, men naturligvis Projser. Han kan noget Dansk og kan forstaa en dansk Opfattelse af Striden, skjøndt han selv er af modsat Mening. 18de Novb. skulde naturligvis have Skyld for Krigen, men tilsidst fik jeg det dog ud af ham, at Pr. slet ikke kunde bestaa som Stormagt uden vore Havne; "da liegt der Hund begraben!« udbrod jeg. -

Paa Kirkegaarden har jeg gjort et andet interessant Bekjendtskab: den katholske Præst, T' r p p e hor n fra Münster, ligeledes en livlig og behagelig Mand med videnskabelige Interesser; han havde ogsaa studeret Dansk, og da han f. T. beskjæftiger sig med Ansgars Levnet, havde dette ført ham til at studere Danske Kildeskrifter i "Scriptores rerum danicarum"; 
han havde ogsaa med megen Interesse læst Deres "De danske Klostre«, samt Kejsers norske Kirkehistorie. Jeg har hørt ham holde 2 charakteristiske Taler over de af deres Saar her Døde. De Danske og Tyske, Katholiker og Protestanter, begraves altid sammen i en Grav, og derfor er jeg med hver Gang og forretter Jordpaakastelsen i Samling med en tysk prot. og en katholsk Gejstlig. (Jeg tror, at det er oftere hændet, at Ingen af de Døde har været Katholik, men paa Dødsanmeldelsen staar, ved D. og Tyske: "Religion unbekannt" - og saa, "for en Fejls Skyld«, er han altid med, da nogle Westphalere ere Katholiker!) Han gaar slet ikke ind paa det speciell Katholske, men den katholske Semipelagianisme træder mærkværdig tydelig frem, f. Ex. forleden Dag, da han sammenlignede Soldaten i Felten med Christus: "paa Ho og Straa i Bethl. - uden det hvortil han kunde helde sit Hoved (Soldaten med Tornystret under Hovedet) forfulgt af sine Fjender og tilsidst dræbt som disse osv. - Dette med Hensyn til det Ydre, og hvad det Indre angik: léd og døde af Lydighed, Soldaterne ligesaa, - uden Synd, det Samme skulde Soldaten stræbe efter, saa vilde han blive salig ligesom den Korsfæstede." Saaledes omtrent, meget populart. En anden Gang: T. og D. laa nu fredelig ved hinandens Side; de havde jo overhovedet ikke haft Noget imod hinandens Personer; det gjaldt kun Sagen. Det kunde Man se af Forposternes Sammenkomster: - "de havde givet hverandre en Taar af deres Feltflaske, foræret hverandre Cigarer og givet hinanden Ild til at tænde dem ved, « - saaledes omtr. verbotenus (ordret), paa Tysk, da. - Ved samme Lejlighed opramses i utrolig Hast lange latinske Psalmer og Bønner med Assistance af en Musik. -Nej, da priser jeg Kapuzineren i Wallensteins Lager! Han skjalder dog godt ud!! - Jeg havde den Tilfredsstillelse forleden Dag, at begge de tyske Præster kom til at fortale sig, idet de sagde om deres Soldater, at de vare komne her til "ein fremdes Land." -

Nu kom F e j l b e r g [Prest i Ullerup] og fortalte, at vi hav- 
de Vaabenstilstand, og Thom a meldte et Øjeblik forud, at vi havde slaaet den tyske Flaade ved Helgoland, og at der var gaaet Ild i en osterr. Fregat. -

Vor B i s k o p [Boesen] faldt hæderlig, fordi han gjorde Indsigelse imod, at der skulde bedes i Hertugd. Slesvigs Kirker "für die Regierung und ihre Räthe u. Diener.» De respecterede Protesten og afsatte ham! (Se: Pilatus i Lidelsesh.!!!)

Torsdag 13/5. 64: - En Hilsen fra os have de da faaet, kan jeg tænke, ved de 3 Borgerrepræsentanter, der laa hos os en Nat paa Vejen til Rendsborg. Den næstfølgende laa her 5 fra Ringk jøbing paa Vejen fra Rborg. De kom Kl. $12^{1 / 2}$ om Natten. Jo, en lustiges Lehen, med Kroater og Ulaner!! - Vi havde i lang Tid dobbelt Indqartering, baade fjendtlig og frivillig, da først B r a m mers [Præstefolkene] fra Egebæk var hos os i 3-4 Uger og saa $\mathrm{K} r$ og $\mathrm{s}$ [Præstefamilien] fra Grumtofte i en halv Snes Dage. Vide [Se] Kapuzineren:

Die Bisthümer sind verwandelt in Wüstthümer, die Abteien und die Stifter sind nun Raubteien und Diebesklüfter!

Men — "noch ist aller Tage Abend nicht!« -

Vor lille Verden her faar en anden Skikkelse, det er vist; men det danske Folk gaar ikke tilgrunde denne Gang; fik vi et Schleswig-Holstein i Personalunion med Kongeriget, ja, da vilde den 3die Slesvigske Krig maaske nok faa en sørgelig Lighed med den 3die puniske; men - som jeg sagde til Hr. B e s s e r Danmark gaar ikke ind derpaa, thi det vilde være at opgive det Hel e. Det halve Slesvig maa dog under alle Omstændigheder kumne frelses ved en Deling, og videre kunne de ikke drive os; men for Øjeblikket - forladte, som vi ere det - er det vel ogsaa det Højeste, vi kunne vente. Selv de dansksindede Flenshorgere, har jeg mærket, ere villige til at gaa ind herpaa under Forudsætning af, at Flenshorg kommer til at hore til Danmark. 
Men: "Qvod adest, memento componere æqvus: cetera fluminis Ritu feruntur.« -")

Lev nu vel og hils alle Deres venligst fra os her; - glem heller ikke gle. Jørgensen !

Deres altid hengivne

G. F. Gr.

Efterskrift 18/5.: Da Brevet ikke kunde afsendes tidligere, kan jeg dog tilføje, at en slesvigsk Fane, som Politimesteren 1. Pints. lod hejse paa den danske Kirke, 2den Pintsed. J)lev nedtaget efter Civilcommissairemes Ordrer, da jeg havde klaget derover. Det var dog en lille Sejer! - - -

*

Den 22. August samme Aar afskedigedes begge Præsterne, da de ikke vilde eller kunde underskrive en Erklæring om at tjene det nye Styre.

H. F. P e tersen.

4) Citatet er ukorrekt, men skal vel omtrent betyde: Husk at faa Sammenhæng i Fakta, det øvrige føres bort af Floclens sarregne Løb. 